Біоінженерія

УДК 615.47

Аврунін О. Г., Носова Я. В., Худаєва С. А.

\title{
ОЦІНКА ДИСКРИМІНАНТНИХ ХАРАКТЕРИСТИК МЕТОДУ КОМП'ЮТЕРНОЇ ОЛЬФАКТОМЕТРІЇ ПРИ ВИЗНАЧЕННІ РЕСПІРАТОРНО-ОЛЬФАКТОРНИХ ПОРУШЕНЬ
}

\begin{abstract}
Проведено статистичну обробку результатів діагностики, щуо підтверджує адекватність моделі незалежної статистичної верифікаиії та дає можливість використовувати запропонований метод при якому в повітряному тракті риноманометра встановлюється одоривектор, а пачієнту пропонується виконати дихальні маневри при фіксуванні моменту часу, при якому досягається нюхальна чутливість з послідуючим визначенням енергетичних характеристик дихання, для функціональної діагностики дихально-нюхових порушень і тестування респіраторно-нюхової чутливості.
\end{abstract}

Ключові слова: одорівектор, ольфактометрія, риноманометрія.

Постановка проблеми. Проблема визначення респіраторно-ольфакторних порушень $\epsilon$ дуже складною у сучасній оториноларингології, бо потребує комплексного підходу. Для визначення порушень нюху використовуються більшою мірою методи, що базуються на суб'єктивній оцінці досліджуваних (сніффінг стік тест, тест університету Пенсельванії та інші) [1]. Найбільш поширеним та об'єктивним інструментальним методом дослідження респіраторних порушень $є$ метод кількісної оцінки функції носового дихання риноманометрія. Цей метод заснований на вимірюванні перепаду тиску між входом та виходом із носової порожнини та витрати повітря, що пропускається при цьому [2]. Слід прийняти до уваги той факт, що порушення нюху тісно пов'язані із респіраторними. Ольфакторне дослідження може бути критерієм оцінки ринохіругічного втручання, також

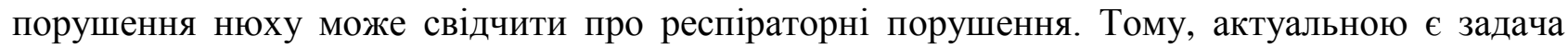
розробки комплексного підходу визначення респіраторно-ольфакторних порушень.

Аналіз останніх досліджень та публікацій. При проведенні передньої активної риноманометрії (ПАРМ) вимірюється витрата повітря $Q$ через один із носових проходів і перепад тисків $\Delta p$ між атмосферним і в носоглотці на вході одного 3 носових ходів геометрично обтурованого за допомогою диференціального датчика, причому дихання здійснюється через інший носовий хід. Достовірність діагностики при цьому значно зменшується через розширення одного носового ходу при обтуруванні іншого, i, як наслідок, неможливість коректного алгебраїчного додавання послідовно вимірюваних витрат повітря $Q_{I_{\text {ПАРм }}}$ та $Q_{\Pi_{\text {ПАРм }}}$ через лівий та правий носові ходи відповідно [3].

Задня активна риноманометрія (ЗАРМ) передбачає вимірювання сумарної витрати повітря $Q$ при диханні носом через обидва носових ходи і перепаду тисків $\Delta p$ між атмосферним і в носоглотці (дистальний кінець вимірювальної трубки датчика тиску вводиться через ротову порожнину) (рис. 1.).

Так як аналіз останніх досліджень та публікацій показав, що метод риноманометрії $\epsilon$ найбільш об'єктивним функціональним методом сучасної лор-діагностики, а метод динамічної задньої активної риноманометрії (ЗАРМ) у порівнянні із передньою активною риноманометрією більш достовірний, то до стандартного методу ЗАРМ пропонується додати визначення деяких параметрів, пов’язаних із функцією нюху. 


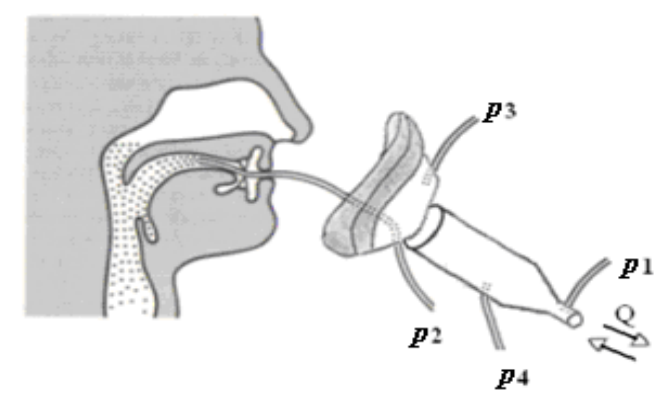

a)

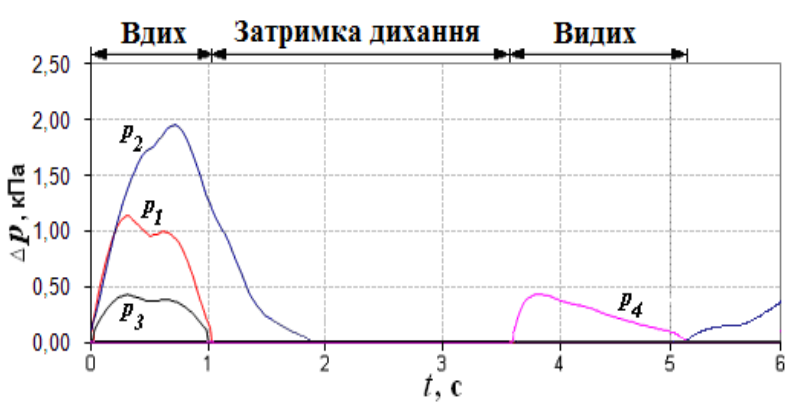

б)

Рисунок 1 - Розташування вимірювальних перетворювачів при ЗАРМ - a та відповідна діаграма дихального циклу - б [3]

Мета дослідження. Метою дослідження $\epsilon$ розробка методу аналізу даних риноольфактометрії для функціональної діагностики дихально-нюхових порушень та оцінка діагностичної значущості запропонованого методу.

Основний матеріал дослідження. Таким чином Була розроблена структурна схема методу об'єктивної діагностики респіраторно-ольфакторних порушень, що враховує вимірювання як аеродинамічних показників носового дихання, так i розрахунок енергетичних характеристик [4-5], за допомогою яких визначається ольфакторна чутливість (див. рис. 2).

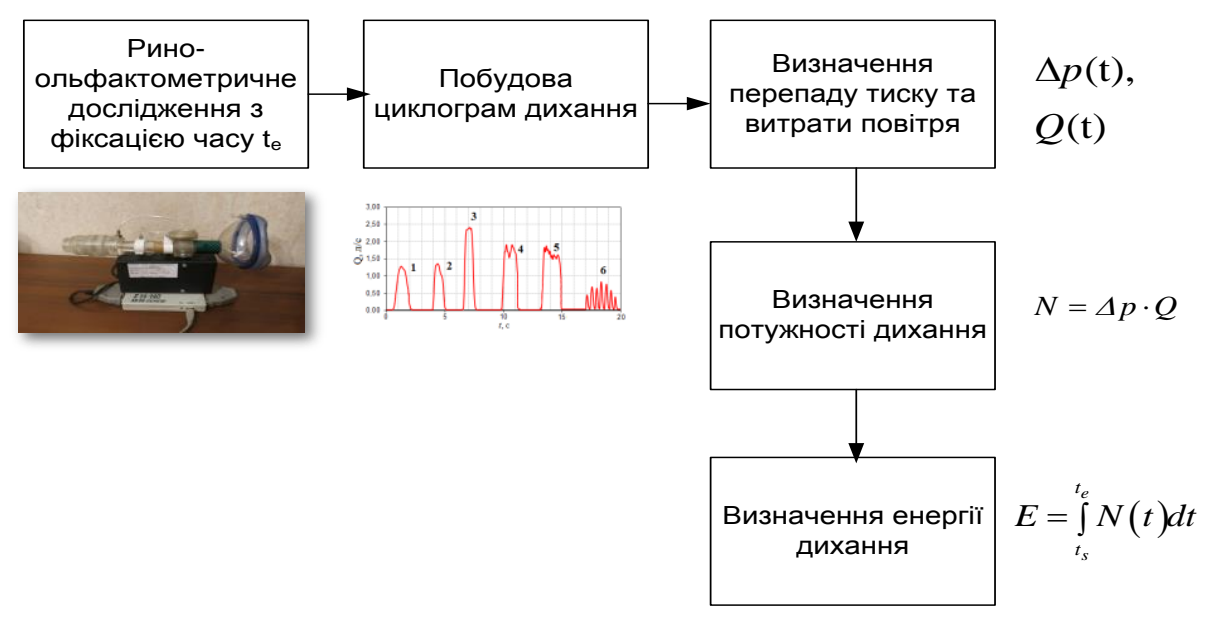

Рисунок 2 - Схема методу аналізу даних риноольфактометрії для функціональної діагностики дихально-нюхових порушень

Проведемо оцінку діагностичної значущості запропонованого методу аналізу даних риноольфактометрії з урахуванням додаткових параметрів - необхідно враховувати час $\mathrm{i}$ потужність дихання при настанні порога відчуття одорівектора значень $Q_{s}$ та $\Delta p_{s} \equiv p_{s}$, що характеризують точку переходу режиму течії повітря в турбулентний квадратичний. Розглянемо модель лінійної дискримінації для 2-х станів об'єкта ( $\Theta_{0}-$ умовна норма, $\Theta_{1}-$ стан при дихально-нюхових порушеннях). Нормована Евклідова відстань між контрольованими станами $\Theta_{0}$ та $\Theta_{1}$ при взаємній незалежності $\mathrm{n}$ ознак обчислюється за формулою [6-7]: 
$2019 \mathrm{p}$.

Вип. 20

\section{Біоінженерія}

$$
\delta=\sqrt{\sum_{i=1}^{n}\left(\frac{m_{i}^{(0)}-m_{i}^{(1)}}{\sigma_{i}}\right)^{2}},
$$

де $m_{i}^{(0)}, m_{i}^{(1)}$ - середні значення $i$-ї ознаки величини $X$ для умов $\Theta \in \Theta_{0}$ (умовна норма), та $\Theta \in \Theta_{1}$ (порушення носового дихання) відповідно,

$\sigma_{i}$ - середньоквадратичні відхилення $i$-ї ознаки, що визначаються згідно до виразу:

$$
\sigma_{i}=\max \left(\sigma_{i}^{(0)}, \sigma_{i}^{(1)}\right) \text { при } \sigma^{(0)^{2}} \neq \sigma^{(1)^{2}},
$$

де $\sigma_{i}^{(0)}, \sigma_{i}^{(1)}$ - середньоквадратичні відхилення $i$-го ознаки для умов $\Theta \in \Theta_{0}$ (умовна норма), та $\Theta \in \Theta_{1}$ (порушення носового дихання).

При нормальному розподілі значень вимірюваної величини ймовірність помилки другого роду при прийнятті рішень про стан об'єкта визначається через інтеграл ймовірності Лапласа $\Phi(\cdot)$ [8] і оцінюється нерівністю

$$
P_{o u} \leq 1-\Phi(\delta / 2)
$$

де $\delta$ визначається за формулою (1).

3 формул (1) і (2) очевидно, що ймовірність помилки тим менше, чим більше нормований по дисперсії квадрат Евклідової відстані між векторами середніх значень ознак.

У запропонованому в методі комп'ютерної ольфактометрії враховують час $\mathrm{i}$ потужність дихання при настанні порога відчуття одорівектора присутні наступні вимірювані фізичні величини (при кількості вимірюваних параметрів $n=5$ ):

$X_{1}$ - максимальна витрата повітря $Q$;

$X_{2}$ - перепад тиску $\Delta p \equiv p$ при максимальній витраті повітря;

$X_{3}$ - витрата повітря $Q_{s}$ при появі нюхової чутливості;

$X_{4}$ - перепад тиску $\Delta p_{s} \equiv p_{s}$ при появі нюхової чутливості;

$X_{5}-$ час $t_{s}$ появи нюхової чутливості.

Стани умовної норми і порушення носового дихання позначаються, відповідно, як $\Theta_{0}$ та $\Theta_{1}$. Всього було обстежено 85 пацієнтів, розділених на дві групи: 40 осіб без порушень носового дихання та 45 осіб з порушеннями носового дихання. При цьому визначалися максимальні значення витрати повітря $Q$ та перепаду тиску $\Delta p$ в носовій порожнині (стандартний метод форсованої ЗАРМ [8]), а також при проведенні комп'ютерної ольфактометрії значення витрати повітря $Q_{s}$ та перепаду тиску при появі нюхової чутливості при подачі відповідного одорівектора. Потім, для кожної групи пацієнтів, розраховувались статистичні показники: середні значення та середньоквадратичні відхилення відповідних вимірюваних величин в нормі та при дихально-нюхових порушеннях. Результати розрахунку нормованої евклідової відстані для оцінюваних показників методу наведені в табл. 1 та відображаються на графіку на рис. 3, а. Зниження ймовірності помилки діагностичного 
$2019 \mathrm{p}$.

\section{Біоінженерія}

Вип. 20

рішення по мірі додавання досліджуваних параметрів в модель дискримінації наведено на рис. 3 , б.

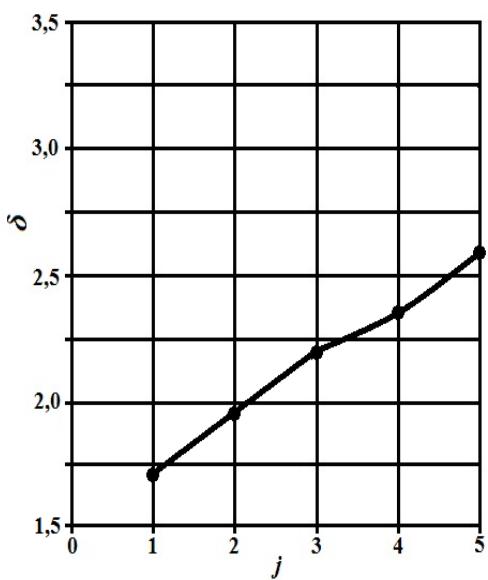

a)

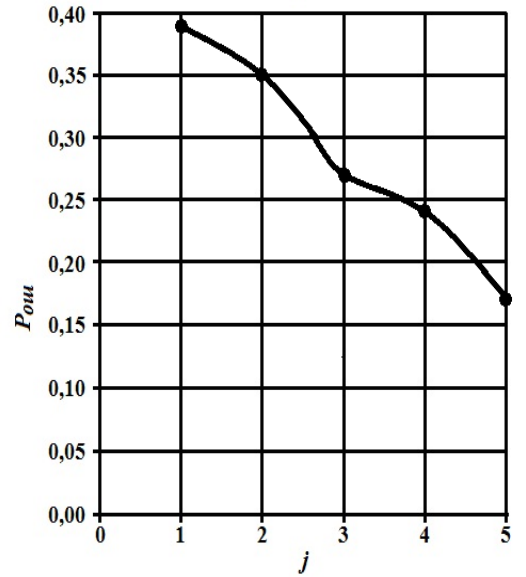

б)

Рисунок 3 - Залежності збільшення нормованої Евклідової відстані (а) та зменшення ймовірності помилки прийняття рішення (б) по мірі додавання ознак модель 1 - для сигналу витрати повітря; 2 - для сигналу перепаду тиску;

3 - витрата повітря при появі нюхової чутливості, 4 - перепад тиску при появі нюхової чутливості, 5 - час появи нюхової чутливості

Таблиця 1 - Результати дискримінантного аналізу для методу аналізу даних тесту комп'ютерної ольфактометрії з додатковими параметрами, що враховують час і потужність дихання при настанні порога відчуття одорівектора

\begin{tabular}{|c|c|c|c|c|c|}
\hline \multirow{2}{*}{\multicolumn{2}{|c|}{ Параметр }} & \multicolumn{2}{|c|}{ Стани } & \multirow{4}{*}{$\begin{array}{c}\text { Нормована } \\
\text { Евклідова } \\
\text { відстань } \delta_{\Sigma} \\
1,71\end{array}$} & \multirow{4}{*}{$\begin{array}{c}\text { Імовірність } \\
\begin{array}{c}\text { помилки } \\
P_{\delta_{\Sigma}}\end{array} \\
\leq 0,39\end{array}$} \\
\hline & & \multirow{2}{*}{$\begin{array}{c}\text { Норма } \\
\Theta_{0} \\
2,64\end{array}$} & \multirow{2}{*}{$\begin{array}{c}\text { Поруш. } \\
\Theta_{1} \\
1,07\end{array}$} & & \\
\hline \multirow[b]{2}{*}{$X_{1}$} & $O$, л/c & & & & \\
\hline & $\sigma_{O}$ & 0,92 & 0,46 & & \\
\hline \multirow[b]{2}{*}{$X_{2}$} & $\Delta p$, кПа & 3,75 & 2,44 & \multirow{2}{*}{1,94} & \multirow{2}{*}{$\leq_{0,35}$} \\
\hline & $\sigma_{\Delta p, \kappa \Pi а}$ & 1,41 & 0,97 & & \\
\hline \multirow{2}{*}{$X_{3}$} & $Q_{s}$, л/с & 0,32 & 2,40 & \multirow{2}{*}{2,22} & \multirow{2}{*}{$\leq_{0,27}$} \\
\hline & $\sigma_{Q_{s}}$ & 0,11 & 1,89 & & \\
\hline \multirow{2}{*}{$X_{4}$} & $\Delta p_{S}$, кПа & 1,55 & 4,61 & \multirow{2}{*}{2,36} & \multirow{2}{*}{$\leq_{0,24}$} \\
\hline & $\sigma_{\Delta p_{s}}, \kappa \Pi а$ & 0,72 & 3,86 & & \\
\hline \multirow{2}{*}{$X_{5}$} & $t_{s}$, кПа & 1,43 & 8,52 & \multirow[t]{2}{*}{2,62} & \multirow{2}{*}{$\leq_{0,17}$} \\
\hline & $\sigma_{t_{s}}$, кПа & 0,35 & 6,19 & & \\
\hline
\end{tabular}




\section{Біоінженерія}

При цьому очевидно, що додавання аеродинамічних показників $Q_{S}, t_{s}$ та $\Delta p_{S}$ точки переходу в турбулентний квадратичний режим течії повітря збільшує нормована Евклідова відстань у порівнянні зі стандартним методом форсованої ЗАРМ на величину 0,68 (в 1,4 раза) та відповідно знижує ймовірність помилки діагностики в 2 рази (с 0,35 до 0,17$)$.

Причому можна помітити, що найбільший внесок в зменшення ймовірності помилки роблять витрата повітря, як при стандартній форсованій риноманометрії, так і при ольфактометрії, а також час появи нюхової чутливості на одорівектор. Перепади тиску не чинять істотної ролі на модель дискримінації.

\section{ВИСНОВКИ}

Встановлено, що для оцінки респіраторних порушень нюху доцільно використовувати енергетичні критерії носового дихання, пневматичну потужність та енергію носового дихання при дії відповідного одоривектора. Для оцінки респіраторних порушень нюху необхідно використовувати метод, при якому в повітряному тракті риноманометра встановлюється одоривектор, а пацієнту пропонується виконати дихальні маневри 3 послідовним нарощуванням інтенсивності дихання при фіксуванні моменту часу, при якому досягається нюхальна чутливість 3 послідуючим визначенням енергетичних характеристик дихання. Проведено статистичну обробку результатів діагностики, що підтверджує адекватність моделі незалежної статистичної верифікації та дає можливість використовувати даний метод для функціональної діагностики дихально-нюхових порушень і тестування респіраторно-нюхової чутливості. Показник ймовірності помилки 2-го роду становить 0,17.

\section{Список використаних джерел:}

1. Olfactometry diagnostic at the modern stage / O. Avrunin, N. Shushlyapina, Y. Nosova, O. Bogdan // Вісник Нац. техн. ун-ту «ХПІ» : зб. наук. праць. Серія : Нові рішення в сучасних технологіях = Bulletin of NTU «KhPI». Series : New solutions in modern technologies. - Kharkiv: NTU «KhPI». - 2016. - N 12 (1184). - C. 95-100.

2. Ismail Saied, H. F. An Attempt of the Determination of Aerodynamic Characteristics of Nasal Airways / H. F. Ismail Saied, A. K. Al_Omari, O. G. Avrunin // Image Processing \& Communications, challenges 3. - 2011. - AISC 102. - P. 311-322.

3. Аврунин, О.Г. Методы и средства функциональной диагностики внешнего дыхания: монография / О.Г. Аврунин, Р. С. Томашевский, Х.И. Фарук.- Харьков : ХНАДУ. - 2015. - 208 c.

4. Nosova, Ya. V. A tool for researching respiratory and olfaction disorders / Nosova, Ya. V., Kh.I. Faruk, O.G. Avrunin // Telecommunications and Radio Engineering (English translation of Elektrosvyaz and Radiotekhnika). - 2018. - Vol. 77 (15). - P. 1389-1395. DOI: 10.1615/TelecomRadEng.v77.i15.90

5. Nosova, Ya. V. Biotechnical system for integrated olfactometry diagnostics / Ya. V. Nosova, O. G. Avrunin, V. V. Semenets // Innovative technologies and scientific solutions for industries. - 2017. - N 1 (1). - P. 64-68. DOI:10.30837/2522-9818.2017.1.064.

6. Cole, P. Contemporary rhinomanometry / P. Cole, R. Fenton // J. Otolaryngol.2006. - N 35 (2). - P. 83-87.

7. Щапов, П. Ф. Повышение достоверности контроля и диагностики объектов в условиях неопределенности : монография / П.Ф. Щапов, О.Г. Аврунин.- Харьков : ХНАДУ, 2011. - 192 с. 
$2019 \mathrm{p}$.

Вип. 20

Біоінженерія

8. Аврунин, О.Г. Сравнение дискриминантных характеристик риноманометрических методов диагностики / О. Г. Аврунин, В. В. Семенец, П. Ф. Щапов // Радіотехніка. - 2011.164. - С. 102-107.

Аврунин О. Г., Носова Я. В., Худаева С. А.

\title{
ОЦЕНКА ДИСКРИМИНАНТНЫХ ХАРАКТЕРИСТИК МЕТОДА КОМПЬЮТЕРНОЙ ОЛЬФАКТОМЕТРИИ ПРИ ОПРЕДЕЛЕНИИ РЕСПИРАТОРНО-ОЛЬФАКТОРНЫХ НАРУШЕНИЙ
}

\begin{abstract}
Ольфакторные исследования могут быть критерием оиенки ринохиругического вмешательства, также нарушение обоняния может свидетельствовать о респираторных нарушениях. Поэтому актуальной является задача разработки комплексного подхода определения респираторно-ольфакторных нарушений. Была разработана структурная схема метода объективной диагностики респираторно-ольфакторных нарушений, учитывающая измерения как аэродинамических показателей носового дыхания, так $u$ расчет энергетических характеристик, с помощьью которых определяется ольфакторная чувствительность. Проведена оченка диагностической значимости предложенного метода анализа данных риноольфактометрии с учетом дополнительных параметров - необходимо учитывать время и мощность дыхания при наступлении порога ощущения одоривектора значений $Q_{s}$ и $\Delta p_{s} \equiv p_{s}$, характеризуюших точку перехода режима течения воздуха в турбулентный квадратичный. Установлено, что для оченки респираторных нарушений обоняния иелесообразно использовать энергетические критерии носового дыхания, пневматическую мощность и энергию носового дыхания при действии соответствующего одоривектора. Для оценки респираторных нарушений обоняния необходимо использовать метод, при котором в воздушном тракте риноманометра устанавливается одоривектор, а пачиенту предлагается выполнить дыхательные маневры с последовательным наращиванием интенсивности дыхания при фиксировании момента времени, при котором достигается обонятельная чувствительность с последующим определением энергетических характеристик дыхания. Проведено статистическую обработку результатов диагностики, которая подтверждает адекватность модели независимой статистической верификации и дает возможность использовать данный метод для функциональной диагностики дыхательной-обонятельных нарушений и тестирования респираторно-обонятельной чувствительности. Показатель вероятности ошибки 2-го рода составляет 0,17.
\end{abstract}

Ключевые слова: одоривектор, ольфактометрия, риноманометрия.

Avrunin O. G., Nosova Ya. V., Khudaieva S. A.

\section{EVALUATION OF THE DISCRIMINANT CHARACTERISTICS OF THE METHOD OF COMPUTER OLFACTOMETRY IN DETERMINING RESPIRATORY AND OLFACTORY DISORDERS}

Olfactory studies can be a criterion for evaluating rhinosurgical intervention, and olfactory impairment may indicate respiratory impairment. Therefore, the urgent task is to develop an integrated approach to determining respiratory and olfactory disorders. A structural scheme was developed for the method of objective diagnosis of respiratory and olfactory disorders, taking into account the measurement of both the aerodynamic parameters of nasal breathing and the calculation of energy characteristics, which are used to determine olfactory sensitivity. The

Режим доступу: http://sap.pstu.edu 
$2019 \mathrm{p}$.

Вип. 20

\section{Біоінженерія}

diagnostic significance of the proposed method of analyzing rhinofolipometry data with regard to additional parameters was assessed - it is necessary to take into account the time and power of breathing when the threshold of sensation of the odor vector $Q_{s}$ and $\Delta p_{s} \equiv p_{s}$ the values characterizing the transition point of the airflow mode to the turbulent quadratic. It has been established that it is advisable to use the energy criteria of nasal breathing, pneumatic power and energy of nasal breathing under the action of the corresponding odor vector for the assessment of respiratory impaired olfactory. To assess the respiratory impairment of olfactory, it is necessary to use the method in which an odor vector is installed in the air path of the rhinomanometer, and the patient is asked to perform breathing maneuvers with a consistent increase in respiration rate while fixing the time at which olfactory sensitivity is achieved and then determining the respiratory energy characteristics. A statistical processing of diagnostic results was carried out, which confirms the adequacy of the model of independent statistical verification and makes it possible to use this method for the functional diagnosis of respiratory-olfactory disorders and testing of respiratory-olfactory sensitivity. The probability index of the error of the second kind is 0.17.

Keywords: odorector, olfakometry, rhinomanometery.

Рецензент: проф., д-р техн. наук Бых А. І.

Стаття надійшла 25.02.2019 p.

\section{УДК 615.47}

Жемчужкина Т. В., Носова Т. В., Семенец В. В.

\section{РАЗРАБОТКА БИОТЕХНИЧЕСКОЙ ЭЛЕКТРОМИОГРАФИЧЕСКОЙ СИСТЕМЫ}

Хроническая боль в спине является распространенной и серьезной проблемой как $c$ медицинской, так и с экономической точки зрения. Оценка состояния мыши спины проводится по результатам электромиографического обследования во время физической нагрузки. Результаты электромиографического исследования тесно связаны со степенью напряжения и растяжения мыши, а качество выполнения физических упражнений паииентом может определяться сопровождающей болью или ее боязнью. В связи с этим предлагается дополнить электромиографический комплекс блоками контроля уровня боли и степени разгибания мыши спины.

Ключевые слова: боль в пояснище, мышечная усталость, оптопара, поверхностная электромиография, разгибание, связанный с болью страх, уровень боли, электроэнцефалография.

Постановка проблемы. Боль в пояснице, которая является одной из основных причин инвалидности [1], широко распространена и экономически затратна для общества. По оценкам [2] 80 \% всех взрослых испытывают как минимум один раз боль в пояснице, что влияет на их способность выполнять повседневные действия. Одной из физических характеристик субъектов с хронической болью в пояснице является повышенная утомляемость мышц разгибателей спины во время теста на выносливость нижней части спины. Таким образом, тесты на выносливость мышц разгибателей спины могут сыграть важную роль в оценке дисфункции параспинальных мышц. Поверхностная электромиография (ЭМГ) использовалась для изучения нервно-мышечных механизмов, связанных с мышечной усталостью во время тестов на выносливость. Надежность этой 